\title{
Gene- diet interaction of 18q21.23 rs17782313 locus and dietary patterns in regulation of hypothalamic-pituitary axis hormones and cardio-metabolic risk factors in obesity
}

\author{
Mahdieh Khodarahmi ${ }^{1} \cdot$ Mahdieh Abbasalizad Farhangi ${ }^{2} \cdot$ Mohaddeseh Mohammadi $^{1}$
}

Received: 28 February 2020 / Accepted: 5 March 2020 / Published online: 18 March 2020

(c) Springer Nature Switzerland AG 2020

\section{Dear Editor,}

We appreciate the interest in our article and thank Dr. Beuy Joob for his knowledgeable comments on our study. Non-coding variants (rs17782313) of the MC4R have been related to susceptibility to polygenic obesity [1]. Therefore, we agree that additional SNPs within the MC4R gene, also SNPs in other genes implicated in the pathogenesis of obesity and cardio-metabolic factors, may be involved, and these should be considered and assessed in further studies. However, our study provides valuable information, as a hypothesis, to be evaluated by cohort studies [2, 3]. Moreover, we agree that other lifestyle and environmental factors could affect our observed results and as well as, the confounding role of other unknown factors is undeniable. Further studies should mostly focus on the effect of polygenic interactions between obesity and its metabolic risk factors.

\section{Compliance with ethical standards}

Conflict of interest The authors declare that they have no conflict of interest.
Ethical approval This article does not contain any studies with human
participants or animals performed by any of the authors. Informed consent For this type of study, formal consent is not required.

\section{Reference}

1. Evans DS, Calton MA, Kim MJ, Kwok PY, Miljkovic I, Harris T, Koster A, Liu Y, Tranah GJ, Ahituv N, Hsueh WC (2014) Genetic association study of adiposity and melanocortin-4 receptor (MC4R) common variants: replication and functional characterization of non-coding regions. PLoS ONE 9(5):e96805

2. Mohammadi M, Khodarahmi M, Kahroba H, Farhangi MA (2020) Dietary patterns interact with the variations of $18 \mathrm{q} 21.23$ rs17782313 locus on regulation of hypothalamicpituitary axis hormones and cardio-metabolic risk factors in obesity. Eat Weight Disord. https://doi.org/10.1007/s40519-020-00855-1 (Epub ahead of print)

3. Mahmoudi-Nezhad M, Farhangi MA, Kahroba H (2020) Cocaine and amphetamine regulated transcript prepropeptide gene (CARTPT) polymorphism interacts with Diet Quality IndexInternational (DQI-I) and Healthy Eating Index (HEI) to affect hypothalamic hormones and cardio-metabolic risk factors among obese individuals. J Transl Med 18(1):16. https://doi.org/10.1186/ s12967-020-02208-z

Publisher's Note Springer Nature remains neutral with regard to jurisdictional claims in published maps and institutional affiliations.
Mahdieh Abbasalizad Farhangi

abbasalizad_m@yahoo.com

1 Nutrition Research Center, Tabriz University of Medical Sciences, Tabriz, Iran

2 Drug Applied Research Center, Tabriz University of Medical Sciences, Attar-neishabouri Ave, Golgasht St, 5165665931 Tabriz, Iran 